\title{
DA RESISTENNCIA AO RECONHECIMENTO: ANNE HÉBERT E A LITERATURA DE AUTORIA FEMININA DO QUEBEC
}

\section{Lilian Virginia Pörto* Louise Henrietta Forsyth**}

Resumo: O presente artigo tem como objetivo demonstrar em que medida a obra de Anne Hébert ocupa lugar de destaque no debate das escritas de gênero, em meio às particularidades e transformações pelas quais a província do Quebec passara ao longo do tempo. Buscou-se demonstrar que, apesar de Hébert contemplar o momento histórico e as causas femininas, sua obra não incorre em escrita panfletária, mas de lirismo politicamente engendrado.

Palavras-chave: Anne Hébert. Quebec. Literatura feminina.

\section{INTRODUÇÃO}

$\mathbf{A}$

nne Hébert (1916-2000), escritora quebequense, é detentora de vasta e toda sorte de produção. Suas publicações compreendem livros de poesia, romance, peças de teatro, novelas e ensaios. Várias delas foram premiadas ${ }^{1}$ e chamaram a atenção da indústria cinematográfica canadense, sendo adaptadas para o cinema, como foi o caso destas três obras: Kamouraska ${ }^{2}$ (1970), por Claude Jutra, em 1973; Les fous de Bassan (1982), por Yves Simoneau, em 1986; Le Torrent (1950), por Simon Lavoie, em 2012.

No Brasil, publicaram-se poemas e textos esparsos em revistas acadêmicas e coletâneas, e alguns de seus livros foram traduzidos na íntegra para o português, como é o caso de Kamouraska, que recebeu o título de A máscara da inocência (1972), por Leônidas Gontijo de Carvalho; de Les fous de Bassan, intitu-

\footnotetext{
Universidade Federal de Goiás (UFG) - Goiânia - GO - Brasil. E-mail: lilianportoufg@gmail.com

* University of Saskatchewan - Saskatoon - Canadá. E-mail: louise.forsyth@usask.ca

1 Informações sobre a bibliografia de Anne Hébert e os prêmios que recebeu estão disponíveis em: <http://www.anne-hebert. com/p.php?i=194>. Acesso em: 28 ago. 2016.

2 Optou-se por não traduzir, neste artigo, títulos de revistas e de obras teóricas e literárias que não foram traduzidas no Brasil.
} 
lado Os gansos selvagens de Bassan (1986), por Vera de Azambuja Harvey; e de La cage (1990), com o título A gaiola de ferro (2003), por Núbia Hanciau ${ }^{3}$.

O universo literário de Anne Hébert é constituído por uma topologia que, não raro, remete ao Quebec e a acontecimentos e ideologias que marcaram a sociedade da época, sobretudo se retomarmos períodos sombrios que abafaram e entravaram a evolução cultural e social da província. Essa época a que nos referimos ficou conhecida como La grande noirceur, ou seja, "A grande escuridão" (1944-1959), período no qual Hébert começa a se inserir no espaço literário. Nas décadas de 1940 e 1950, Quebec encontrava-se sob o governo de Maurice Duplessis, então primeiro-ministro, que mantinha sua população num estado de estagnação social, intelectual e cultural. Conservador, ele defendia os valores tradicionais engendrados nos domínios da religião, da família e da cultura da terra.

Anne Hébert e muitos outros artistas e escritores ousaram combater esse obscurantismo cultural por meio de suas obras - dado que explicaria a desconfiança de Duplessis em relação aos artistas. Por essa razão, é sabido que muitos deles tiveram de partir do Quebec se quisessem ter a liberdade para criar. Como resistência a esse cenário opressor, a obra de Hébert é caracterizada por poemas e narrativas com uma leitura crítica do universo feminino, avultando as limitações e as agressões infligidas à mulher na sociedade quebequense. Nesse contexto em que se concebe um espaço privilegiado para a experiência feminina, vemos mulheres e meninas de todas as idades e classes sociais sendo representadas. Falaremos com mais detalhes sobre isso no curso do presente artigo. Antes, contudo, gostariamos de assinalar alguns dados relevantes da obra de Hébert para a conjuntura da escrita de autoria feminina.

Tem-se que a aparição dos primeiros textos considerados feministas ocorreu por volta dos anos 1960. Para Isabelle Boisclair (2004), o primeiro romance de Hébert, Les chambres de bois (1958), prefigura a revolução feminista quebequense, uma vez que anuncia um programa de emancipação a ser realizado nos anos subsequentes. Se formos pensar em como se afigura a constituição da produção literária feminista no Canadá, não podemos deixar de fazer menção às contribuições dadas pela autora quebequense, já que sua obra se move em direção contrária ao imperativo universo patriarcal, com linhas que se descontentam com a praxe identitária da mulher, sem, no entanto, incorrer no proselitismo barato ou na produção de panfleto. O que vemos é uma escrita literariamente valorada, de lirismo e força política e feminina engendrados. Em tempo: Anne Hébert, além de célebre no mundo francófono, é das autoras mais visitadas pela crítica anglo-canadense, e seus textos são os mais traduzidos para o inglês - entre outros muitos idiomas -, posicionando-se ao lado de escritoras da envergadura de Gabrielle Roy e Marie-Claire Blais (GODARD, 2002, p. 66). Cumpre registrar, ademais, que a fundação do Centre Anne Hébert e da revista Les Cahiers Anne Hébert ${ }^{4}$ dão à autora prestígio e reconhecimento inconteste e abrem espaço para que as discussões de gênero possam ser realizadas livres de afetação ou mero hasteamento de bandeira.

\footnotetext{
Para mais informações a respeito da tradução dessas obras no Brasil, sugere-se a leitura de Pôrto (2012).

Torna-se forçoso registrar o dado de que em junho de 2016 foi realizado, nas cidades de Montréal e Sherbrooke /Quebec, o Colóquio Internacional Anne Hébert para comemorar o centenário do nascimento da escritora (Colloque Anne Hébert, le centenaire).
} 
Posto isso, o presente artigo tem como objetivo demonstrar em que medida a obra de Anne Hébert ocupa lugar de destaque no debate das escritas de gênero. Com isso, observaremos também que a resistência inicial e, finalmente, o reconhecimento da sua obra estão estreitamente ligados às mutações históricas e sociais de sua sociedade de pertença. Para tanto, apresentaremos, a seguir, em breves linhas, algumas das particularidades e transformações pelas quais a província do Quebec passou.

\section{O CONSERVADORISMO NO QUEBEC}

Durante os anos 1940 e 1950, predominou na província do Quebec uma ideologia conservadora impulsionada pelo governo de Maurice Duplessis, conforme assinalado. Mesmo após a Segunda Guerra Mundial, com os avanços da indústria, a sociedade quebequense se mostrava tradicional, clerical e ruralista (MONIĖRE, 1977). Anne Hébert iniciaria suas publicações nesse período, considerado repressivo e conturbado para a vida cultural. A sociedade ${ }^{5}$ era, nesse momento, regida por dogmas da religião católica: o clero supervisionava tudo o que fosse ligado ao domínio artístico e literário (BIRON et al., 2007).

$\mathrm{Na}$ literatura, predominavam temáticas que visavam promover o apego à terra e à valorização de famílias numerosas, características da chamada literatura do Terroir, isto é, literatura de verve rural, que predominaria no cenário literário canadense francês até 1945.

Diante desse controle de costumes e comportamento considerados subversivos, os primeiros textos de Anne Hébert foram censurados. Le Torrent (1950) e Le tombeau des rois (1953) são exemplos disso. É oportuno esclarecer que o conteúdo de Le Torrent era perturbador para a sociedade até então denominada canadense francesa, a qual incentivava famílias numerosas e valorizava mães altruístas a serviço da fé católica e da preservação da cultura e língua francesas. Ocorre que, em Le Torrent, Anne Hebért desconstrói essa concepção ideológica tradicional da figura da mulher ao trazer à baila a figura de uma mãe má, Claudine Perreault, que, numa atitude tirana, acaba aniquilando o filho, François Perreault. Este, por sua vez, provoca a morte de sua própria mãe e, ao fazê-lo, imprime um valor transgressor à ideia tradicional que tributa ao amor maternal a condição de incondicionalidade. Com esse cenário perturbador, Anne Hébert teve a publicação de seu livro impedida. A escritora não conseguiu, pois, encontrar no Quebec nenhum editor disposto a compartilhar a ideia de que a religião pudesse ser, de outra parte, responsável pela violência materna. É certo que Claudine é representada como uma mãe cruel, que tenta impedir o filho de viver, mas, ainda assim, é preciso não esquecer - e o texto de Hébert o faz bem - que ela, ao ser expulsa de seu vilarejo por ser mãe solteira, é também vítima de uma ideologia clerical. Na obra de Hébert, as mulheres mostram-se insatisfeitas com a vida de privações que levam, rejeitando, por vezes, os valores tradicionais prezados pela sociedade quebequense de diferentes épocas: 1840 (Kamouraska), 1936 (Les fous de Bassan) e 1950 (Le Torrent). Em Le Torrent, por exemplo, é possivel depreender que os dogmas da religião privam a mulher de sua identidaCumpre destacarmos, inclusive, que o sistema escolar público quebequense até os anos 1960 era controlado exclusivamen-
te pela Igreja. As alunas não tinham direito de estudar no nível secundário, tampouco de continuar os estudos em níveis superiores. 
de e fazem com que ela destrua a vida dos filhos quando transmite a eles os valores que pregam a culpabilidade e a submissão cega às leis da Igreja.

Diante desse cenário de repressão que limitava a produção artística e literária, alguns grupos despertaram o desejo de lutar em prol de melhores condições de vida e liberdade de expressão para o povo canadense francês. O descontentamento da população intelectual diante das limitações impostas pelo governo de Duplessis abalaria, então, as bases do conservadorismo. Em 1948, um grupo de artistas, homens e mulheres, inspirados no surrealismo francês, se juntou ao pintor Paul-Émile Borduas com o intuito de publicar um manifesto, que viria a se chamar Refus global ("Recusa total"). Tal manifesto apresentou-se como oposição ao obscurantismo cultural e à ordem estabelecida no Quebec, demonstrando ser um legítimo canal de denúncia dos valores conservadores e religiosos ali vigentes para promover uma verdadeira transformação social por meio da arte (SMART, 1998).

Acompanhando esse movimento de reivindicações, os anos de 1960 são significativos para a história do Quebec porque também influenciaram a vida literária da província. Esse periodo ficou conhecido como a Révolution tranquille ("Revolução tranquila"), nome que viria a designar um conjunto de reformas iniciadas entre 1960 e 1966, durante o governo do liberal Jean Lesage, e cujo slogan de campanha dizia: "Il faut que ça change" ("É preciso mudar"). A partir daí, uma série de transformações ideológicas passou a ocorrer no Quebec.

Inicialmente, passa-se do "respeito às tradições" ao "desafio do progresso"6: o conservadorismo político e clerical e o imobilismo social e intelectual são sucedidos por uma fase de progresso e mudanças sociais e culturais (MONIËRE, 1977, p. 261). Os ideais e os desejos de transformação que antes habitavam o espírito de alguns grupos de intelectuais são tomados pela maioria da população que reivindica a circulação livre de opiniões. Nesse contexto, a religião católica perde poder sobre a sociedade, encerrando-se, então, a era da chamada equivalência entre católico e francês (MONIĖRE, 1977).

Por ter promovido uma série de transformações politicas, econômicas e culturais na sociedade quebequense - com ressonâncias na língua, educação, religião, artes e letras, família, mídia, costumes, trabalho e sindicalismo -, a Révolution tranquille (1960-1966) ficou conhecida como o periodo responsável pelo despertar identitário do Quebec. Os artistas foram os principais propagadores desse espírito de progresso que contagiou a província. A partir de então, a expressão "canadense francês" é deixada de lado, e seus habitantes passam a se autodenominar "quebequenses", que, para eles, simbolizaria um modo de registrar na lingua as marcas de uma identidade própria. Nos anos seguintes, sob exigência da população, os governos fundariam instituições que lhes permitiriam aumentar o nivel de instrução e também socioeconômico de seu povo, bem como impor o francês como língua de uso público (BOUCHARD, 2012).

Essas transformações ocorridas durante a Révolution tranquille influenciaram também a literatura do Quebec, que deixou de ser conhecida como "literatura canadense francesa", para, a partir daí, ser chamada de "literatura quebequense". Essa alteração terminológica é significativa por duas razões: 1. porque traz a lume a necessidade de se produzir uma literatura numa variedade de

6 No original: "respect des traditions; défis du progrès". Todas as citações redigidas em língua estrangeira foram traduzidas pelas autoras, salvo quando indicado diferentemente. 
francês que consiga imprimir a identidade e a história do povo de Quebec (BOUCHARD, 2012), além de vincular seu nome ao espaço geográfico em que se encontra inserida; 2 . porque essa literatura deixou de estar ligada ao único projeto de sobrevivência nacional (BIRON et al., 2007) que caracterizara os anos antecedentes à Révolution. Graças a essas reformas, a literatura passa a interrogar a identidade nacional: percebe-se que os textos escritos durante esse periodo se ocuparam muito mais em questionar essa identidade do que em afirmá-la (BIRON et al., 2007). Com efeito, o resultado disso foi um aumento significativo de publicações. A ideologia progressista da Révolution tranquille parece, pois, ter criado um ambiente favorável ao desenvolvimento do romance feminino (BROWN, 1992). Nesse particular, é necessário esclarecer que a literatura escrita por mulheres é importante em todas as épocas da história literária do Quebec, mas que, antes dos anos 1960, o número de mulheres escritoras é sensivelmente menor do que o de homens escritores (BROWN, 1992). Essa diferença é compreensivel se retomarmos o contexto histórico e social da sociedade tradicional canadense francesa, em que as mulheres eram vistas apenas como servas da família e, portanto, desprovidas do acesso à educação e/ou a uma vida profissional. Após um período de tímidas publicações por escritoras, nota-se, durante a década de 1960, uma produção mais significativa de romances escritos por mulheres.

A partir dos anos 1970, surge, sobremaneira, uma série de reivindicações politicas e estéticas que influenciaram a literatura do Quebec, entre elas, o feminismo ${ }^{7}$. Seguiram-se anos de contestação e de rupturas, mas também de um desenvolvimento significativo da literatura quebequense, impulsionado por uma época de reformas que viria desencadear uma produção artística de relevância. Esse período ficou marcado por uma efervescência cultural. Assim, ao lermos Anne Hébert, podemos observar: 1. que a autora viveu todas essas transformações que foram paulatinamente perturbando e transformando a sociedade quebequense; 2 . que sua obra, mesmo não se filiando a uma literatura militante e engajada, não deixa de revelar sua preocupação com os problemas que marcaram aquele tempo, e que "[a] trajetória de sua obra vincula-se à mutação sócio-cultural do Quebec, proscrevendo valores ultrapassados, ligando a libertação pessoal dos personagens - mulheres e homens - à libertação coletiva" (HANCIAU, 1995, p. 150).

Nesse sentido, é possivel constatar que algumas personagens hebertianas expressam os desejos de liberdade da sociedade quebequense, conforme se pode atestar pelo manifesto Refus global (BORDUAS, 1948). Esse manifesto, redigido por Borduas e assinado por 15 artistas (desse total, sete são mulheres), denuncia e repudia a sociedade tradicional e clerical quebequense, reivindicando a liberdade de expressão. Borduas (1948) convida os quebequenses a se voltar contra a opressão e a se juntar a ele e aos signatários desse manifesto para reivindicar liberdade. Essa necessidade de libertação encontra-se impressa na maioria das personagens de Anne Hébert que, por sua vez, começa a publicar seus livros durante o período marcado por manifestações contrárias ao poder conservador estabelecido no Quebec. Elisabeth d'Aulnières, personagem de $\mathrm{Ka}$ -

Esclarecemos que o ano de 1970 é enfatizado, nesse ponto, por causa do renascimento do movimento feminista organizado no Quebec (SAINT-MARTIN, 1997), que, por sua vez, influenciou a literatura quebequense desse período. Cumpre esclarecer ainda que a história do feminismo, no Quebec, começou muito antes dos anos 1970, conforme assinala Michèle Jean (1979, p. 18). 
mouraska, aspira a uma liberdade que nunca poderá alcançar no Quebec católico e tradicional de 1840. Irmã Julie, personagem de Les enfants du sabbat, por sua vez, revolta-se contra a alienação do indivíduo, mais precisamente contra a alimentada no bojo de uma instituição católica, advinda do convento do Précieux sang ("Precioso sangue") - referência representativa de uma sociedade dominada pela ideologia tradicional e clerical dos anos 1930 e 1940. Nora Atkins, personagem de Les fous de Bassan, criada numa comunidade minoritária protestante, brada aos quatro cantos o seu desejo de explorar o mundo e, em 1936, reivindica a igualdade entre homens e mulheres. Não é por acaso que evocamos essas personagens femininas de Hébert para exemplificar o selvagem desejo de liberdade que persegue suas criações, já que o tema da libertação do indivíduo, como se pode perceber, atinge especialmente as mulheres de sua obra.

\section{ESCRITA FEMININA, ESCRITA FEMINISTA, ÉCRITURE AU FÉMININ}

Esse clima de mudanças estruturais e ideológicas que acabamos de descrever continua influenciando grupos de escritores, intelectuais e artistas que desejam o desenvolvimento social e cultural do Canadá francês. Nessa perspectiva, a literatura também se transforma, e novas escritas surgem na cena literária, entre elas, a que se convencionou chamar de escrita feminina, praticada majoritariamente por mulheres. A partir dos anos 1960, mulheres militantes e escritoras lutam para garantir uma maior participação feminina na esfera pública. Revistas feministas surgem, mais particularmente no decorrer dos anos 1970 e 1980, dentre elas, vale citarmos: Québécoises deboutte! (1969-1974), Les têtes de pioche (1976-1979) e La vie en rose (1980-1987).

Na literatura, escritoras publicam obras que são, veementemente, rotuladas de feministas. Entre essas escritoras, estão: Madeleine Gagnon (Pour les femmes et tous les autres, 1974), Louky Bersianik (L'Euguelionne, 1976), Luce Guilbault et al. (La Nef des sorcières, 1976), Nicole Brossard (L'Amèr ou Le Chapitre effrité, 1977), Denise Boucher (Les Fées ont soif, 1977) e France Théoret (Nécessairement putain, 1980) que buscaram imprimir, em suas obras e ensaios críticos, a afirmação da mulher enquanto sujeito crítico, repelindo a imagem feminina da condição de objeto e vítima da ideologia patriarcal.

Esses primeiros textos são, pois, marcados pelo espírito da luta feminista e por uma consciência aguçada da exclusão do feminino na linguagem. Com efeito, são por vezes textos considerados portadores de uma escritura assinalada pela revolta, pela violência e pelo engajamento político. Muitas dessas autoras ligadas ao movimento de literatura feminista se ocuparam tanto em discutir o papel das mulheres - sob a égide da lingua e das ideologias - quanto, e principalmente, com o ato da escrita em si, que, para Nicole Brossard, pode ser percebido como um verdadeiro ato político (RESCH, 2009).

Anne Hébert dá início à publicação de seus livros antes da formação de uma consciência feminista em literatura no Quebec, porém seus primeiros poemas e narrativas trazem em seu cerne uma leitura crítica do universo feminino, ao revelarem as opressões, limitações e agressões infligidas à mulher na sociedade quebequense. Embora a escrita de Hébert seja considerada clássica por alguns críticos e escritores (THÉORET, 1987), cumpre dizer que a autora não oculta e nem marginaliza o universo feminino. Pelo contrário, a denúncia da violência física e psicológica exercida contra a mulher é revelada pela autora por meio de 
uma escrita que confere destaque às contradições da existência e que pode ser lida como reflexo de uma sociedade patriarcal opressora. Reiteramos que a obra hebertiana destina um espaço privilegiado à experiência feminina, quando ali se encontram representadas mulheres e meninas de todas as idades e classes sociais. As personagens femininas, nesse caso, vêm imbuídas de vivências, dores, medos, ambições e sonhos. Algumas chegam até mesmo a expressar revolta (Les enfants du sabbat) e a incitar (Kamouraska) ou a exercer (Le Torrent) atos de violência.

Sucede que ao atribuir à personagem feminina uma posição de destaque na narrativa, valorizando-a enquanto sujeito, Hébert provoca "a transgressão de um número importante de convenções literárias ligadas à imagem da mulher, resultantes na manutenção do status quo" (BROWN, 1992, p. 144-145). Fato é que a partir do momento em que Hébert dá voz à personagem feminina, fazendo-a falar em primeira pessoa, como ocorre em Kamouraska (1970), a autora provoca uma ruptura com a tradição literária quebequense que ainda se encontrava habituada em apresentar narradores majoritariamente homens e ocupados, portanto, em narrar a história sob o ponto de vista única e exclusivamente masculino. Hébert não parece se preocupar com causas nacionais com enfoque nos grandes embates - temas valorizados antes da explosão da escrita feminina e feminista nos anos 1960 e 1970. A autora opta por privilegiar o universo doméstico, familiar, enfim o cotidiano em que suas heroínas estão inseridas, o que não significa que, com isso, negligenciasse o contexto histórico e social, mas que estivesse mais interessada em enfatizar o ponto de vista feminino imerso num determinado espaço e tempo. Lembramo-nos aqui de Béatrice Didier (1981, p. 37), quando afirma que a escrita feminina é uma escrita do "interior do corpo, interior da casa"

Nesse ponto, torna-se necessário esclarecer que várias escritoras quebequenses diferenciam modos de escrita surgidos no contexto da literatura feminina quebequense. Entre elas, destacamos, por exemplo, Nicole Brossard, Louise Dupré e France Théoret (LOTBINIĖRE-HARWOOD, 1991), que tratam de três expressões recorrentes para designar essas modalidades de escrita, são elas: écriture féminine ("escrita feminina"), écriture féministe ("escrita feminista") e écriture au féminin ("escrita no feminino"). France Théoret (1987), referindo-se aos textos decorrentes dessa nova configuração ideológica, afirma que a escrita feminina é comumente entendida como obras literárias que não questionam, na linguagem, os estereótipos femininos. Já a escrita feminista remete a escritos, ensaios, manifestos, testemunhos, enfim, a textos não literários, que tenham como princípio politizar. Quanto à chamada escritura no feminino, refere-se a textos literários em que o sujeito feminino é consciente de seu lugar de inscrição.

A expressão escrita feminista é empregada, muitas vezes, para se referir a obras de escritoras como Nicole Brossard, Louky Bersianik, entre outras, mas também é comumente utilizada para mencionar textos teóricos que não são artísticos. Por esse motivo, para essas escritoras, a expressão que melhor reflete a escrita de mulheres - gesto ao mesmo tempo político e poético - é écriture au féminin, pois ela busca enfatizar a especificidade de um projeto feminista que é,

\footnotetext{
8 No original: "la transgression d'un nombre important de conventions littéraires liées à l'image de la femme, et qui avaient pour résultat le maintien du statu quo".

9 No original: "I'intérieur du corps, I'intérieur de la maison".
} 
ao mesmo tempo, pessoal, político, estético, ontológico e epistemológico. Mais: a écriture au féminin apresenta uma reflexão explícita no próprio texto, quer seja a respeito do funcionamento ideológico da língua, quer seja sobre a sua recepção por parte do leitor, bem como acerca do próprio ato de escrever (FORSYTH, 2010). Finalmente, o que caracteriza a écriture au féminin no Quebec, segundo Nicole Brossard (1998, p. 84), "é, primeiramente, a sua inscrição na modernidade da escrita quebequense, sua inserção numa problemática da linguagem e do simbólico" ${ }^{\text {. }}$.

É pertinente observar que essas terminologias (escrita feminina, escrita feminista e écriture au féminin) procuram dar conta da especificidade de certos textos. Porém, rotular uma obra com uma dessas etiquetas não é tarefa fácil, pois pode provocar contradições e impropérios. Convém lembrar que Louise Dupré (1989) sugere que a escritura de Anne Hébert deve ser arrolada à categoria da escrita feminina, mas tal classificação, a nosso ver, parece inapropriada, já que a crítica afirma que a escrita feminina é aquela que apresenta "traços de uma feminilidade na textualidade, sem que haja vontade de uma busca pelo feminino nem perspectiva feminista alguma"11 (DUPRÉ, 1989, p. 24). Dupré (1989) reconhece que as obras de arte resistem a qualquer tipo de definição e observa que mesmo as primeiras coletâneas de poesias de Nicole Brossard estão mais próximas de uma escrita feminina do que de uma écriture au féminin; mas, ainda assim, não se furta de afirmar que, em Hébert, não há perspectiva feminista alguma impressa. É importante sublinhar que as pesquisas sobre a obra hebertiana, sobretudo a partir dos anos 1990 e mesmo nos anos 1980 - como se observa, por exemplo, em "Distance, point de vue, voix et idéologie dans Les fous de Bassan d'Anne Hébert” (BISHOP, 1984) -, já reconheciam no texto hebertiano a recusa da ideologia dominante e das imagens estereotipadas da mulher.

Partindo dessas observações, constatamos como as ideologias e manifestações sociais e culturais podem influenciar os modos de leitura que lhe são contemporâneos e que a compreensão dessas teorizações acerca da escrita feminina, elaboradas no Quebec, auxilia a conhecer melhor o meio literário e social de pertença da escritora em estudo. Assim,

[...] quebequense, feminista, a obra hebertiana também permanece: canadense-francesa, marcada pelas estruturas ideológicas e sociais que pesaram sobre a infância e a juventude da autora, e, não obstante, sobre sua revolta contra várias delas"12 (BISHOP, 1993, p. 210).

Esse descontentamento e essa revolta são vividos por várias das personagens de Hébert, especialmente pelas mulheres, o que evidencia a preocupação da autora com questões de sua época, como as que dizem respeito ao gênero, ao feminismo e, finalmente, ao lugar de inscrição da mulher na sociedade quebequense. Lembramos que o romance Kamouraska foi publicado em 1970, ano em que as discussões e pesquisas feministas já estavam em estágio avançado no Quebec. É pertinente assinalar que, embora esse romance não apresente o nível de consciência de inscrição do sujeito feminino no texto (retomando a definição

10 No original: "c'est d'emblée son inscription dans la modernité de l'écriture québécoise, son insertion dans une problématique du langage et du symbolique".

11 No original: "des traces d'une féminité dans la textualité, sans qu'il y ait volonté d'une recherche sur le féminin ni aucune perspective féministe".

12 No original: "québécoise, féministe, l'œuvre hebertienne reste aussi : canadienne-française, marquée par les structures idéologiques et sociales qui ont pesé sur l'enfance et la jeunesse de l'auteure, et nonobstant sa révolte contre plusieurs d'entre elles". 
de écriture au féminin proposta por France Théoret), tampouco promova uma discussão explícita das assimetrias do poder patriarcal, percebe-se nele, e em toda a obra hebertiana, uma certa intenção, por parte da autora, em participar dos problemas de sua época, porém, à sua maneira, cumpre ressalvar.

Discreta, Anne Hébert, quando lhe perguntam se milita em algum movimento, responde que é possivel militar de maneira indireta, apresentando, por exemplo, meninas e mulheres com personalidade forte. A autora acrescenta: "Ao não retratá-las como pequenos seres frágeis, exprimo a minha concepção de mulher e, dessa maneira, deposito minha fé sobre ela"13 (HÉBERT apud BISHOP, 1993, p. 199). Percebemos nessa fala que a autora pretende conscientizar a sociedade de que é necessário se reestruturar ideologicamente (BISHOP, 1993). Importa ainda observar que a figura do homem na obra de Anne Hébert é quase sempre representada ora como indivíduo fraco, ora como agressor patriarcal momentâneo. Para as escritoras que praticam a escrita feminista ou a écriture au féminin, a transformação da mulher de objeto para sujeito se dá, sobretudo, por meio da subversão explícita da linguagem e de suas ideologias. Entretanto, cumpre advertir que a desfamiliarização da forma e da linguagem literárias não tem em si mesma nenhuma relação automática com os objetivos políticos do próprio feminismo (FELSKI, 1989).

Partindo disso, lembramos que a personagem feminina hebertiana é representada como sujeito, porém os modos de subversão contra a ordem estabelecida não são necessariamente a subversão do léxico nem da sintaxe, e, sim, outros. As obras da autora são testemunho de uma luta permanente "para contornar o papel tradicional reservado à mulher, a fim de passar do status de objeto ao de sujeito, seja pela subversão, perversão, sedução, denúncia; ou ainda movido pelo sentimento de revolta"14 (HAYWARD, 1993, p. 149).

Desse modo, pode-se dizer que a obra de Hébert provoca a tradição de diferentes maneiras, seja pelo tratamento da figura da mulher, seja pela libertação de certas convenções literárias: muitas vezes, a autora não se preocupa em manter uma narração linear, tampouco em respeitar as formas consideradas tradicionais na escrita de poesia (BIRON et al., 2007). Assim é que forma e conteúdo, não raro, conversam entre si no processo de transgressão. Em outras palavras: os aspectos intelectual, social, politico e cultural de Anne Hébert fundem-se, tributando sua escrita "sensivel à condição feminina, sensibilidade que é transformada em solidariedade e engajamento" (HANCIAU, 1999, p. 323). Todos esses aspectos também produziram textos críticos, conforme destacamos anteriormente, escritos que assinalam temas relevantes para o feminismo e que podem ser lidos em Anne Hébert: o relacionamento entre mãe e filha, a sexualidade das mulheres, a dificuldade da mulher de passar do status de objeto para sujeito, enfim, a opressão que exerce a sociedade patriarcal sobre as mulheres. Lembremo-nos novamente de Rita Felski (1989, p. 7) que afirma: "uma relação entre literatura e feminismo somente pode ser estabelecida se um texto aborda temas de algum modo relevante para as preocupações feministas"15.

13 No original: "En les montrant autrement que comme de petits êtres fragiles, j'exprime ma conception de la femme, je fais en quelque sorte un acte de foi en elle".

14 No original: "pour contourner le rôle traditionnel réservé à la femme afin de faire passer du statut d'objet à celui de sujet, que ce soit par la subversion, la perversion, la séduction, la dénonciation ou carrément la révolte".

15 No original: "a link between literature and feminism can only be established if a text addresses themes in some way relevant to feminist concerns". 
Como se pode notar, o conceito de literatura feminista ou de perspectiva feminista se alarga e, consequentemente, a escrita de Hébert também, quando se confere à mulher uma nova condição. Assinale-se que, mesmo depois de ultrapassada a discussão sobre o grau de feminismo na obra de Anne Hébert, essa continua sendo uma temática que, para alguns, é evidente e, para outros, problemática, visto que a escritora não assume um discurso feminista que beire o panfletário, condição que muitos críticos - talvez os mais radicais - consideram crucial para se legitimar um texto de fato feminista. O que vemos, pois, imperar nessa autora passa ao largo disso. Sua "intenção [é a] de denunciar a violência e as injustiças a que as mulheres são subjugadas"16 (BISHOP, 1993, p. 201). Ressalte-se que Hébert não se filiou a grupo político algum e que sua obra não é vinculada a nenhuma corrente literária no Quebec ou na França (BIRON et al., 2007). Por meio das representações que nos oferece, da trama romanesca, do poder e da eficácia da sua palavra poética, ela apresenta a sua visão de mundo e revela o seu descontentamento em relação à sociedade quebequense de sua época.

Assim, diferentemente de escritoras como Nicole Brossard, France Théoret e Madeleine Gagnon, que são militantes e em cujas obras vemos claramente uma intenção política, Hébert (apud DUBE et al., 1978, p. 33) declara: "eu, eu nunca explico, eu faço ver as coisas, eu as vejo, mas não as explico"17. Com um olhar feminino, a autora não cessa de mostrar que "as mulheres gritam sua angústia, sua tristeza e seu ódio diante de um mundo que as ludibriou"18 (AONZO, 1981, p. 26).

Diante do que foi exposto até aqui, podemos dizer que Anne Hébert é consciente de que a linguagem pode ocultar o feminino, mostrando-se mobilizada por questões ligadas à condição de gênero, ao revelar, entre outras coisas, que o patriarcado não tem nada de triunfante, como observa Marilyn French (1990). Isso posto, torna-se forçoso reconhecer que um texto não precisa falar ou denunciar aberta e diretamente os artificios do patriarcado para oprimir as mulheres. Afinal, "as obras de arte não são mensagens ideológicas, mas explorações da contradição"19 (SMART, 1988, p. 33). Nos escritos de Anne Hébert, saltam aos olhos justamente as contradições sobressalentes de um sistema patriarcal e opressor, que acabam acenando para a impossibilidade de transformação e/ou reconhecimento da mulher e de seu status de sujeito na história (SMART, 1988).

\section{CONSIDERAÇões FINAIS}

Inserida nessa sociedade que, inicialmente, pregava a ideologia conservadora, Hébert não conseguiu encontrar um editor, no Quebec, para que Le Torrent (1950) e Le tombeau des rois (1953) fossem publicados. Esses titulos marcam, segundo alguns críticos, a emergência da escritora na cena literária (BIRON et al., 2007). Le Torrent foi publicado com recursos da própria Hébert, pois foi considerado violento. Quanto às poesias, foram publicadas graças ao escritor Roger Lemelin que assumiu as despesas da impressão. Já o seu primeiro romance, intitulado Les chambres de bois (1958), foi publicado na França pela Éditions du Seuil.

\footnotetext{
16 No original: "I'intention de dénoncer la violence et les injustices que subissent les femmes".

17 No original: "moi je n'explique jamais, je fais voir les choses, je les vois, mais je ne les explique pas".

18 No original: "les femmes crient leur angoisse, leur détresse et leur haine face à un monde qui les a leurrées".

19 No original: "les œuvres d'art ne sont pas des messages idéologiques, mais des explorations de la contradiction".
} 
Fato é que, desde o princípio, a escritora quebequense inquiriu o status quo da sociedade da época, desestabilizando as ideologias veiculadas pelo movimento conservador liderado por Duplessis. A escrita de Hébert expunha, nesse sentido, as fragilidades de um governo que impedia a livre expressão do indivíduo, sua evolução e seu crescimento intelectual. Nesse contexto histórico e social, a escritura de Hébert incomodava porque se tornava "um gesto de revolta e de libertação"20 (EMOND, 1980, p. 111) e que, mesmo não lançando mão das mesmas abordagens utilizadas pelas escritoras reconhecidas como feministas, soube, enfim, denunciar a violência física e psicológica exercida contra a mulher. Essa perspectiva da obra hebertiana, conforme assinalamos, só passou a ser reconhecida e valorizada a partir do desenvolvimento dos estudos feministas no Quebec, ocorrido nos anos 1980, quando de um período em que era preciso "dizer todo o silêncio de um país onde nada deveria morrer nem mudar"21 (EMOND, 1980, p. 111).

\section{From resistance to recognition: Anne Hébert among Québec women writers}

Abstract: This article shows the extent to which Anne Hébert's literary works occupy a prominent place in debates about gender in writing. It pays particular attention to the specifics and the transformations through which Québec passed over time. We have tried to demonstrate that while Hébert was an observer of the historical moment and women's issues, the meaning of her work is conveyed through politically inspired lyricism, not in pamphlet form.

Keywords: Anne Hébert. Quebec. Women's literature.

\section{REFERÊNCIAS}

AONZO, J. La femme dans les romans d'Anne Hébert. 1981. 141 f. Dissertação (Mestrado em Literatura de Língua Francesa)-McGill University, Montréal, 1981.

BIRON, M. et al. Histoire de la littérature québécoise. Montréal: Boréal, 2007. BISHOP, N. B. Distance, point de vue, voix et idéologie dans Les fous de Bassan d'Anne Hébert. Voix et Images, Montréal, v. 9, n. 2, p. 113-129, 1984.

BISHOP, N. B. Anne Hébert, son œuvre, leurs exils. Bordeaux: Presses Universitaires de Bordeaux, 1993.

BOISCLAIR, I. Ouvrir la voie/ $x$ : le processus constitutif d'un sous-champ littéraire féministe au Québec (1960-1990). Montréal: Éditions Nota bene, 2004.

BORDUAS, P. É. Refus global. Saint-Hilaire: Mithra-Mythe Éditeur, 1948.

BOUCHARD, C. Pourquoi la société québécoise entretient-elle des rapports si agités avec la langue ? Petite histoire d'un objet de polémique. Disponivel em: <http://www.panorama-quebec.com/cgi-cs/cs.waframe.content?topic= 45051\&lang=1>. Acesso em: 26 maio 2012.

20 No original: "un geste de révolte et de libération".

21 No original: "dire tout le silence d'un pays où rien ne devait mourir ni changer". 
BROSSARD, N. She would be the first sentence of my next novel. Elle serait la première phrase de mon prochain roman. Tradução Susanne de Lobtinière-Harwood. Toronto: The Mercury Press, 1998.

BROWN, A. Brèves réflexions sur le roman féminin québécois à l'heure de la Révolution Tranquille. In: SAINT-MARTIN, L. (Org.). L'autre lecture: la critique et les textes québécois. Québec: XYZ, 1992. t. I, p. 139-153.

DIDIER, B. L'écriture-femme. Paris: PUF, 1981.

DUBE, C. et al. Anne Hébert: entrevue. Québec Français, Laval, n. 32, p. 33-35, 1978.

DUPRÉ, L. Stratégies du vertige: trois poètes: Nicole Brossard, Madeleine Gagnon, France Théoret. Montréal: Les éditions du remue-ménage, 1989.

EMOND, M. Romanciers du Québec. Québec: Éditions Québec Français, 1980.

FELSKI, R. Beyond feminist aesthetics: feminist literature and social change. Cambridge: Harvard University Press, 1989.

FORSYTH, L. Le genre, la violence, l'écriture et la traduction dans Le désert mauve (1987) de l'écrivaine québécoise Nicole Brossard. Palestra proferida no dia 20 de setembro de 2010, no miniauditório Prof. Egídio Turchi, na Faculdade Letras da Universidade Federal de Goiás.

FRENCH, M. Is there a feminist aesthetic? Hypatia, São Francisco, v. 5, n. 2, p. 33-42, 1990.

GODARD, B. La traduction comme réception: les écrivaines québécoises au Canada anglais. TRT, Montréal, v. 15, n. 1, p. 65-98, 2002.

HANCIAU, N. Os romances de Anne Hébert: uma fonte para o estudo da literatura quebequense. In: BERND, Z.; CAMPOS, M. C. do (Org.). Literatura e americanidade. Porto Alegre: Editora da UFRGS, 1995. p. 137-150.

HANCIAU, N. A representação da mulher na obra romanesca de Anne Hébert. In: BÉLANGER, A.; HANCIAU, N.; DION, S. (Org.). A América francesa: introdução à cultura quebequense. Rio Grande: Editora da Furg, 1999. p. 310-328.

HAYWARD, A. Le roman québécois au féminin avant 1960. "Mère plutôt que femme". In: COLLECTIF. Mises en scènes d'écrivains. Sainte-Foy: Le Griffon d'argile, 1993. p. 149-160.

HÉBERT, A. Kamouraska. Paris: Seuil, 1970.

HÉBERT, A. Le Torrent. Montréal: HMH, 1976.

HÉBERT, A. Les fous de Bassan. Paris: Seuil, 1982.

HÉBERT, A. Les enfants du sabbat. Montréal: Boréal, 1995.

JEAN, M. Histoire des luttes féministes au Québec. Possibles, Montréal, v. 4, n. 1, p. 17-32, 1979.

LOTBINIĖRE-HARWOOD, S. Re-belle et infidèle: la traduction comme pratique de réécriture au féminin. Montréal: Les éditions du remue-ménage, 1991.

MONIĖRE, D. Le développement des idéologies au Québec des origines à nos jours. Montréal: Éditions Québec-Amérique, 1977.

PÔRTO, L. V. Traços feministas em traduções brasileiras de obras de Anne Hébert. 2012. 210 f. Tese (Doutorado em Letras e Linguística)-Universidade Federal de Goiás, Goiânia, 2012. 
RESCH, Y. Écritures au féminin/écritures migrantes, littérature québécoise/ littérature postnationale. In: LALIBERTÉ, R. (Org.). À la rencontre d’un Québec qui bouge: introduction générale au Québec. Paris: Éditions du CTHS, 2009. p. $139-150$.

SAINT-MARTIN, L. Figures de la sorcière dans l'écriture des femmes au Québec. In: SAINT-MARTIN, L. Contre-voix: essais de critique au féminin. Montréal: Nuit Blanche, 1997. p. 165-189.

SMART, P. Écrire dans la maison du père: l'émergence du féminin dans la tradition littéraire du Québec. Québec: XYZ, 1988.

SMART, P. Les femmes du Refus global. Québec: Boréal, 1998.

THÉORET, F. Entre raison et déraison. Montréal: Les Herbes Rouges, 1987.

Recebido em agosto de 2016. Aprovado em novembro de 2016. 